\title{
Optogenetic Control of the Peripheral Nervous System
}

\author{
Rui B. Chang \\ Department of Neuroscience, Department of Cellular and Molecular Physiology, \\ Yale University School of Medicine, New Haven, Connecticut 06520 \\ Correspondence: rui.chang@yale.edu
}

\begin{abstract}
The peripheral nervous system (PNS) is highly complicated and heterogenous. Conventional neuromodulatory approaches have revealed numerous essential biological functions of the PNS and provided excellent tools to treat a large variety of human diseases. Yet growing evidence indicated the importance of cell-type-specific neuromodulation in the PNS in not only biological research using animal models but also potential human therapies. Optogenetics is a recently developed neuromodulatory approach combining optics and genetics that can effectively stimulate or silence neuronal activity with high spatial and temporal precision. Here, I review research regarding optogenetic manipulations for celltype-specific control of the PNS, highlighting the advantages and challenges of current optogenetic tools, and discuss their potential future applications.
\end{abstract}

$T^{\text {he }}$ he peripheral nervous system (PNS) connects body organs and the brain, and is essential for numerous physiology functions and behaviors. The PNS contains two subsystems: the somatic nervous system containing sensory and somatic nerves and the autonomic nervous system, which controls involuntary physiological functions. Anatomically, the PNS is composed of cranial nerves, spinal nerves, and local neural networks around body organs (Catala and Kubis 2013; Karemaker 2017). Cranial nerves, which originate from the brain, link organs in the head and neck region, including skin, muscle, eye, tongue, ear, nose, larynx, and pharynx, with the central nervous system. Organs below the head are generally innervated by spinal nerves. Many essential specific sensory modalities such as vision, smell, taste, hearing, and balance are carried by cranial nerves. Somatosensations, including touch, pain, temperature, and visceral sensation, are also conducted by sensory fibers within cranial and spinal nerves. Spinal sensory fibers travel through dorsal roots of the spinal cord, with their cell bodies located in dorsal root ganglia (DRG). Muscle movements in the head and neck region are controlled by cranial nerves, while spinal motor fibers that directly innervate their effector muscles in the lower body exit the spine from ventral roots.

Some cranial nerves and spinal nerves are sensory or motor only, while others contain a mixture of fibers for sensory, motor, or autonomic roles. A unique member of the cranial nerves, the vagus nerve (also known as the cranial nerve $\mathrm{X}$ or $\mathrm{CN} \mathrm{X}$ ), provides both sensory

Editors: Valentin A. Pavlov and Kevin J. Tracey

Additional Perspectives on Bioelectronic Medicine available at www.perspectivesinmedicine.org

Copyright (C) 2019 Cold Spring Harbor Laboratory Press; all rights reserved; doi: 10.1101/cshperspect.a034397

Cite this article as Cold Spring Harb Perspect Med 2019;9:a034397 
(afferent) and motor (efferent) autonomic innervation to organs in the upper and lower body. In the head and neck region, this includes larynx and pharynx, but also many lower body organs, including lung, heart, blood vessel, esophagus, stomach, intestine, liver, kidney, and pancreas (Berthoud and Neuhuber 2000). Majority of parasympathetic preganglionic neurons that innervate organs in the head reside in cranial ganglia (Wehrwein et al. 2016; Karemaker 2017). Their downstream targets, parasympathetic postganglionic neurons, are located within or near their target organs. Vagus parasympathetic (motor) fibers innervating visceral organs project directly from the dorsal nucleus and nucleus ambiguus in the brainstem. On the other hand, sympathetic neurons are contained in spinal nerves. Preganglionic neurons originated from the spinal cord travel a short distance to synapse with postganglionic neurons with cell bodies located in bilaterally symmetric sympathetic chain ganglia or the collateral ganglia. Such postganglionic neurons then send long projections to control their target visceral organs. Another large subset of the PNS is composed by local neural networks around visceral organs, such as the enteric nervous system, which is composed by $\sim 500$ million neurons lining the gastrointestinal tract in human (Furness 2012). Similar neural networks are also described for the cardiovascular system (Armour et al. 1997). These local neural plexuses interact extensively with visceral organs as well as sensory and motor autonomic nerve fibers. They can function independently as local reflexes and work together with the sympathetic and parasympathetic nervous system to coordinately regulate organ physiology.

Dysregulation of the PNS is associated with numerous diseases, and thus neuromodulation in the PNS has been a great interest for more than a century. Surgery, pharmacology, and electrical stimulation are common approaches to modulate peripheral nerve activities. Surgical denervation of selective nerve branches is used to treat a diverse range of diseases. For example, vagotomy was one of the most popular surgeries for treatment of duodenal and gastric ulcer disease during the 1970s and 1980s and is still in use in some emergency operations (Woodward 1987; Lipof et al. 2006). Cervicothoracic sympathectomy was used to treat patients with hyperhidrosis (excessive sweating), vasospastic conditions (e.g., Raynaud's disease), and angina pectoris (chest pain) for many decades (Drott 1994). Endoscopic thoracic sympathectomy that removes part of the thoracic sympathetic nerve trunk is still a modern procedure to treat patients with focal hyperhidrosis (Cerfolio et al. 2011). Stellate ganglion block, achieved by injecting local anesthetic into the stellate ganglion, is commonly used to reduce pain and has been considered for treating arrhythmia (Nademanee et al. 2000; Jeon 2016). A targeted lung denervation procedure launched by Nuvaira is currently on clinical trial for the treatment of severe asthma (Wolter 2018). In addition, discoveries of receptors, ion channels, signaling molecules, and other proteins critically involved in PNSrelated diseases over the past few decades prominently facilitated the design of pharmaceutical drugs. Recently, extensive research has been applied to investigate bioelectronic devices to achieve peripheral nerve stimulation. Surgically implanted vagus nerve stimulation (VNS) devices are clinically used to treat patients with drug-resistant refractory epilepsy and severe, recurrent unipolar and bipolar depression (Schachter and Saper 1998; Rush et al. 2000; Uthman 2000; Groves and Brown 2005; O’Reardon et al. 2006; Krahl 2012; Yuan and Silberstein 2016a). Many VNS-based clinical trials have been conducted or are currently ongoing for treating inflammatory and cardiovascular diseases (Gold et al. 2016; Koopman et al. 2016; De Ferrari et al. 2017; Bonaz 2018; DiCarlo et al. 2018). In animal studies, VNS is being investigated for treatment of numerous diseases, including acute asthma, acute kidney injury, hypertension, heart failure, inflammation, blood glucose management, and metabolic syndromes (Das 2011; Sabbah et al. 2011; Hoffmann et al. 2012; Chapleau et al. 2016; Inoue et al. 2016; Meyers et al. 2016; Ardell et al. 2017; Pavlov and Tracey 2017; Kim et al. 2018; Pavlov et al. 2018). Noninvasive VNS approaches are also being investigated, and the first noninvasive VNS therapy was approved in late 2017 for acute 
Optogenetic Control of Peripheral Nervous System

treatment of cluster headache (Siefring 2017) and later for the treatment of migraine pain (Brauser 2018).

Although existing neuromodulatory approaches are powerful tools, and being used for research in animal studies and also for human therapies, multiple fiber types, including sensory, motor, or autonomic fibers, are almost always affected by these techniques. However, the PNS is a highly heterogenous system. A wide variety of neurotransmitters and neuropeptides are used in the PNS (McCorry 2007; Wehrwein et al. 2016). Parasympathetic preganglionic neurons are largely cholinergic, using acetylcholine to communicate with their postganglionic targets. The primary neurotransmitter in parasympathetic postganglionic neurons is also acetylcholine, although other neurotransmitters, including nitric oxide and vasoactive intestinal polypeptide (VIP), are active as well (Travagli and Anselmi 2016). Likewise, sympathetic preganglionic neurons rely on acetylcholine to activate nicotinic acetylcholine receptors on postganglionic neurons. Unlike the parasympathetic system, sympathetic postganglionic neurons control their target functions primarily using norepinephrine, classified as adrenergic neurons. Other neurotransmitters such as acetylcholine, epinephrine, and dopamine are also released by sympathetic postganglionic neurons for some targets (Murphy and Elliott 1990; McCorry 2007). Sensory neurons in the glossopharyngeal nerve (cranial nerve IX), the vagus nerve (cranial nerve $\mathrm{X}$ ), the trigeminal nerve (cranial nerve V), and DRG are largely glutamatergic. Neuropeptides such as VIP, CGRP, and substance $\mathrm{P}$ present in subsets of sensory neurons and their physiological roles still need to be fully determined (Levine et al. 1993; Zhuo et al. 1997; de Lartigue 2014; Goto et al. 2017). To an extreme extent, more than 30 neurotransmitters are used by neurons in the enteric nervous system (McConalogue and Furness 1994; Costa et al. 2000). Cell heterogeneity in different tissues has continued to be explored over the past decades. Numerous novel cell types in regions that were previously thought to be homogenous have been identified using novel microfluidics-based, massively parallel single-cell transcriptome analysis (Macosko et al. 2015; Habib et al. 2017; Rodda et al. 2018). Cell heterogeneity in peripheral ganglia and the enteric nervous system has previously been reported, and more cell types will certainly be discovered in the PNS going forward. Yet the existing tools, including electrical stimulation, surgical perturbation, and pharmacological modulation, can hardly provide insights at a cell-type-specific resolution, calling for new neuromodulatory technologies and approaches in the PNS. Recent developments and applications for optogenetic tools in peripheral nerves are outlined below.

\section{APPLICATION OF OPTOGENETICS IN THE PERIPHERAL NERVOUS SYSTEM}

Optogenetics is a powerful neuromodulatory technology that combines optics and genetics to achieve neuronal activation or inhibition in selected neurons (Boyden 2011; Deisseroth 2015). Optogenetic tools evolved rapidly since the pioneer work, which demonstrated the powerful effect of channelrhodopsoin ChR2based light stimulation in controlling neuronal activity in mammalian neurons (Boyden et al. 2005; Li et al. 2005; Nagel et al. 2005). Nowadays, optogenetics is widely used in animal studies for research regarding neural circuits, neuronal functions, and behaviors. In general, choice of opsins, gene-targeting methods, expression levels, light delivery approaches, and appropriate controls are the major aspects that need to be considered when conducting optogenetic studies.

Opsins for optogenetics are light-gated ion channels that belong to the large family of microbial opsins (Fig. 1; Zhang et al. 2011; Deisseroth 2015). As one of the most commonly used opsins for neuronal activation, channelrhodopsin2 (ChR2) identified from green alga is a blue light-gated nonselective cation channel that offers multiple ideal features for in vitro and in vivo neural stimulation (Boyden et al. 2005; Li et al. 2005; Nagel et al. 2005). First, light stimulation of ChR2 leads to large photocurrents and potent depolarization when expressed in neurons. This is important as minimum light can be used for neuronal activation, which is espe- 
R.B. Chang

A

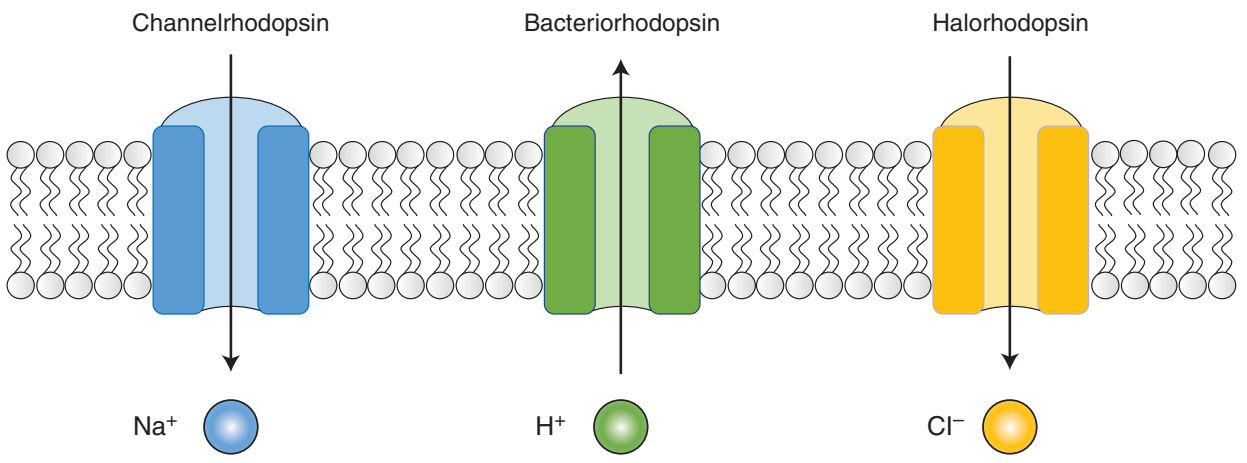

B

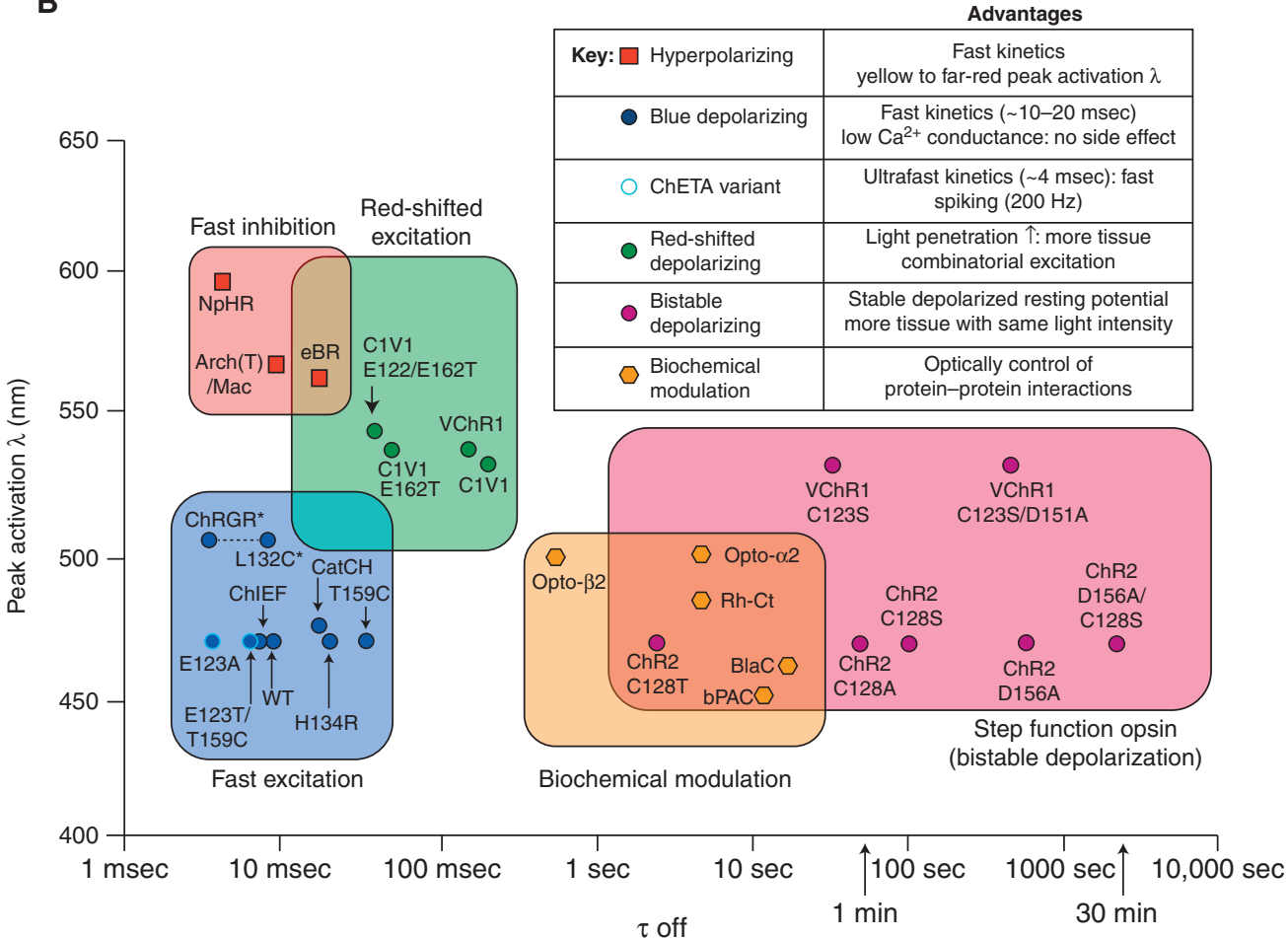

Figure 1. Light-activated microbial opsins in optogenetics. (A) Schematic illustration of the three major classes of microbial opsins for neuronal inhibition and activation. (B) Summary of most available opsins for optogenetic studies. (Panel B from Gerits and Vanduffel 2013; reprinted, with permission, from Elsevier (C) 2013.)

cially critical for in vivo applications. Second, because of the fast activation and relaxation kinetics of ChR2, neuronal activation can be achieved repeatedly in a temporal precision manner at a millisecond scale. Today, a large number of channelrhodopsin variants with improved photocurrents, kinetics, light sensitivity, and trafficking efficiency are available. ChR2
(H134R), a ChR2 variant with a single amino acid mutation, has an improved channel conductance and photocurrents with minimal sacrifice of kinetics and is widely used for a variety of in vitro and in vivo applications (Nagel et al. 2005; Madisen et al. 2012). Chronos, a channelrhodopsin discovered from Stigeoclonium helveticum that has a superior temporal resolution 
with super-fast on and off kinetics is ideal for high-frequency neuronal stimulation (Klapoetke et al. 2014). As optogentic tools get better, a next goal is to achieve better tissue penetration for in vivo applications and to expand the optimal light stimulation spectrum for independent activation of multiple opsins simultaneously at different wavelengths. A number of channelrhodopsins with red-shifted action spectrum were developed for these purposes. VChR1, the first reported red-shifted channelrhodopsin discovered from Valvax, is maximumly excited with green light around 545 $\mathrm{nm}$ and can still be activated with orange light at $589 \mathrm{~nm}$ (Zhang et al. 2008). Nevertheless, photocurrents of VChR1 is small and its trafficking efficiency in neurons is not ideal. A few engineered variants with similar wavelength sensitivity but enhanced photocurrents and trafficking efficiency were later developed, including C1V1 and ReaChR (Yizhar et al. 2011; Lin et al. 2013). These improved opsins are great for deep tissue stimulation; however, as their wavelength sensitivity is quite broad, they can still be activated with blue light and are not ideal for multiwavelength stimulation with ChR2 for activation of distinct neuron types. Chrimson, a more red-shifted channelrhodopsin discovered from Chlamydomonas noctigama with maximum activation at $590 \mathrm{~nm}$ was developed (Klapoetke et al. 2014). Chrimson has large photocurrents at far-red $660 \mathrm{~nm}$ and is minimally activated at $470 \mathrm{~nm}$ compared to other channelrhodopsin variants. Now, it is possible to combine ChR2 and Chrimson together to achieve independent activation of two neuron populations.

A variety of microbial opsins are also developed to inhibit neuronal activities, including variants of halorhodospins, light-activated chloride pumps discovered from halobacteria, and archaerhodopsins, light-activated outward proton pumps found in Archaea. As both chloride and proton currents decrease neuronal excitability, halorhodopsins and archaerhodopsins are inhibitory. NpHR, a halorhodopsin from Natronomonas pharaonic, and Arch/ArchT, proton pumps from Halorubrum sodomense and Halorubrum strain TP009, respectively, are widely used for inhibitory optogenetics (Han and Boyden 2007; Zhang et al. 2007; Gradinaru et al. 2008; Chow et al. 2010; Madisen et al. 2012). A series of revisions with improved photocurrents and trafficking efficiencies have been developed. While the most current versions, eNpHR3.0, eArch3.0, and eArchT3.0, all have large photocurrents and fairly wide sensitivity across green, yellow, and red wavelengths, eNpHR3.0 is more red-shifted than the Archs (maximum activation at $590 \mathrm{~nm}$ vs $535 \mathrm{~nm}$ ) (Mattis et al. 2012). All three are effective in neuronal silencing and have been applied for a variety of neuron types in vitro and in vivo, although it is worth noting that all three opsins require a relatively high light power density and thus may not be ideal for silencing a large volume of tissue. Another concern for inhibitory opsins is that unlike gain-of-function experiments that involve pulsed light stimulation, loss-of-function experiments often require chronic illumination, which may lead to current decay, depletion of ion sources, and tissue damage. Compared to channelrhodopsins, efficiencies of inhibitory opsins in neuronal silencing are more cell-type-dependent.

A big advantage of optogenetic tools compared to conventional neuromodulatory approaches (e.g., electrical, surgical, pharmacological, thermal, etc.) is the compatibility with genetics. In model organisms such as fruit fly and mouse, microbial opsins can be easily delivered to target neuron populations using a variety of genetic approaches to achieve celltype-specific manipulation. In particular, diverse transgenic fly and mouse models exist and are publicly available. In mice, opsins can be transgenically expressed under a specific gene promoter (Arenkiel et al. 2007), be inserted in situ to either replace the target gene or after the target using an internal ribosome entry site (Wang and Zylka 2009; Smear et al. 2013), or be introduced using DNA recombinase-based technologies such as the Cre-LoxP system (Madisen et al. 2012; Zeng and Madisen 2012). A few things need to be considered before generating a transgenic mouse tool. First, expression of foreign genes in genetically targeted cells is usually more accurate in knockin animals compared 
to transgenic. Second, the expression level is usually not a concern unless using a weak endogenous promoter, and is relatively stable across animals. Third, although the Cre-LoxP system has enabled optogenetics in diverse neuron types, and many mouse lines for Cre-dependent optogenetics are publicly available, spatial and temporal specificity is usually a concern. Viral delivery is another common strategy for both in vitro and in vivo studies (Deisseroth 2015; Montgomery et al. 2016). Compared to transgenic mouse models, viral delivery requires less mouse-generating efforts, is suitable for more cell types, and may give better temporal and spatial specificity. The expression level of introduced opsins can usually be controlled by adjusting (1) amount of virus used, (2) titer of the virus, (3) promoter, and (4) time after infection. Promoters commonly used for neurons include EF1 $\alpha$, CamKII, and hSyn. High-expression levels can be achieved by using different promoters such as CAG, which can be beneficial for some cases. On the other hand, viral delivery usually requires surgery, which introduce additional complications. Viral infection may elicit immune responses and cause more cell damage. Viral delivery may introduce additional variance among experiments, such as variabilities in number of infected cells and expression levels of opsins. In particular, overexpression can be problematic and may lead to cell sickness. Cell health usually needs to be closely monitored and assessed after viral infection. Some examples will be discussed in the following sections.

Lasers or high-powered, light-emitting diodes (LEDs) are great options for light stimulation in vivo. Within the brain, light delivery is usually achieved using an optic fiber cannula placed right above target neurons through a hole drilled through the skull (Sparta et al. 2012). The cannula is secured onto the skull with dental cement to ensure stability. This approach is widely used in both anesthetized and awake, freely behaving animals. As an optic fiber is needed to connect the light source with brain cannula, the animal is tethered in this strategy. Within the PNS, light delivery is easier to achieve for in vitro or ex vivo applications as well as for in vivo anesthetized animal preps using an externally positioned light source (Maksimovic et al. 2014; Chang et al. 2015; Williams et al. 2016; Nonomura et al. 2017), but is considerably harder for most studies that require awake animals (Fig. 2). Transdermal light illumination is widely used for optogenetic stimulation of peripheral nerves with nerve endings on or beneath the skin (Ji et al. 2012; Daou et al. 2013, 2016; Boada et al. 2014; Draxler et al. 2014; Iyer et al. 2014; Park et al. 2016). A few optic cuffbased strategies were developed for light illumination of large peripheral nerve trunks inside animal bodies (Towne et al. 2013; Michoud et al. 2018). In these applications, light delivery was achieved using an optic cuff made with optic fibers, wire-coupled LEDs, or wireless LEDs (Fig. 2). Nevertheless, these optic cuff-based devices function very well in larger animals with thicker nerve trunks but present significant challenges in small animals like mice because of surgical difficulties and tiny nerve size. An alternative strategy is to illuminate nerve or nerve endings on the organ surface using LED meshes (Samineni et al. 2017a). Specificity and efficacy are usually the major factors that need to be considered when using this approach. Recent advances in red-shifted opsins provide an opportunity for noninvasive deep-tissue stimulation, although their applications in peripheral nerves deep inside visceral organs still need to be demonstrated. Genetically encoded light sources like luciferase-based bioluminescence that generate light in response to externally administered substrates may provide effective internal illumination. Such tools basically convert optical stimulation to chemical stimulation. In particular, by fusing bright luciferase and redshifted channelrhodopsins together, light stimulation efficacy can be significantly improved. Such bioluminescence tools have been applied to a few neuron types for in vivo stimulation (Land et al. 2014; Berglund et al. 2016). Although still in its early stage, a bioluminescence-based approach may provide powerful light sources for internal optogenetic stimulation in the future. Overall, light delivery approaches for awake animal studies in the PNS are still in a relatively early development stage and need to be examined in more applications. 
A

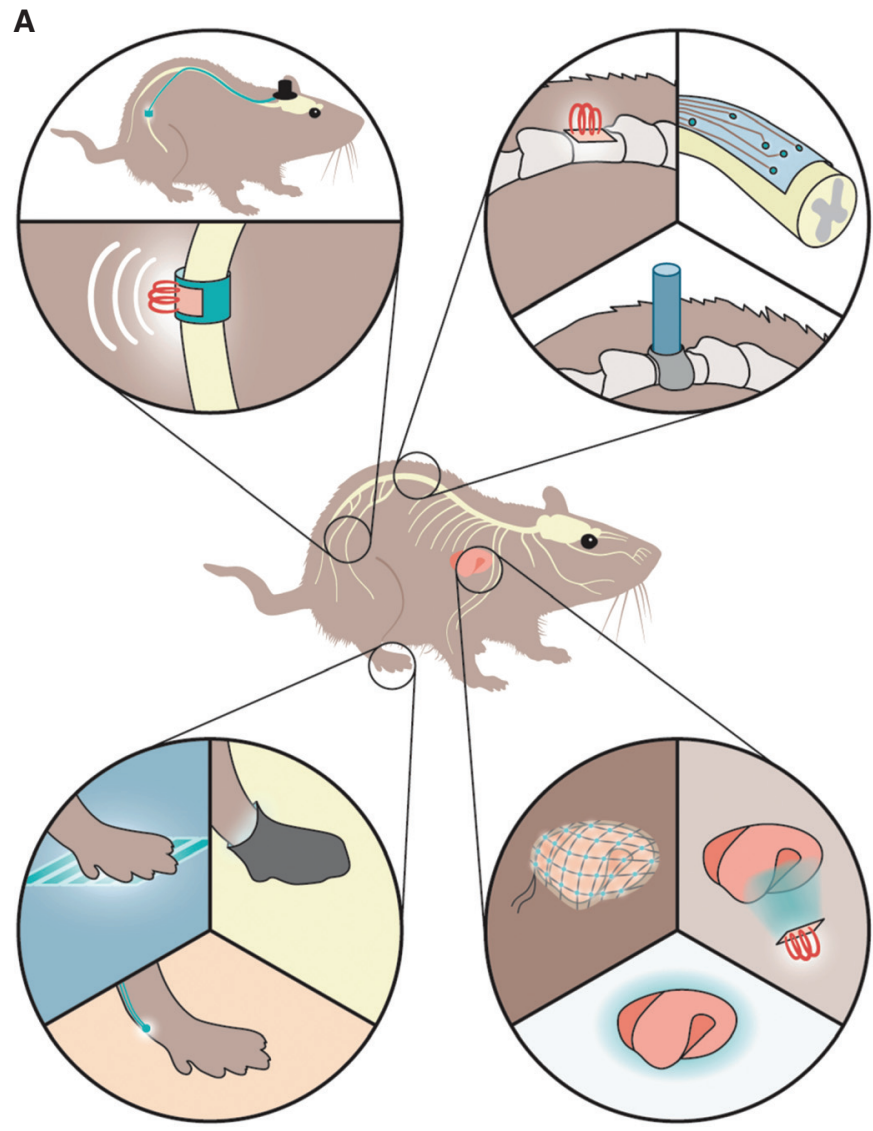

B

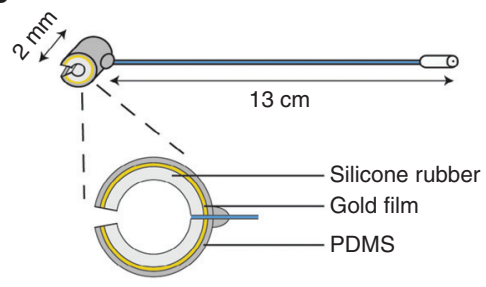

C

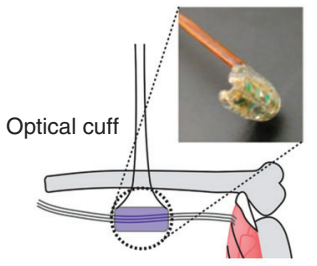

D

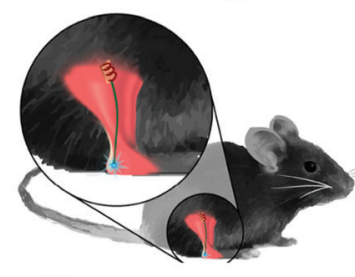

E

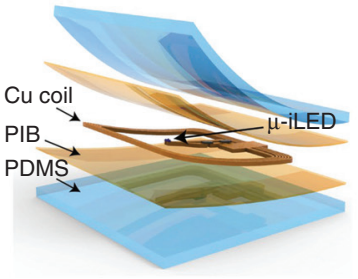

Figure 2. Light delivery methods for optogenetic studies in awake, freely moving rodents. (A) Schematic illustration of super soft and flexible optic cuff for optogenetic neuromodulation of large peripheral nerves, the spinal cord, nerve endings, and internal organs. (Panel based on data in Montgomery et al. 2016.) (B) Illustration of an optic fiber-based optic cuff implant for sciatic nerve stimulation in awake, freely moving mice. (Panel reprinted from Michoud et al. 2018 courtesy of IOP Publishing in conjunction with Creative Commons Licensing.) (C) Illustration of a micro LED-based optic cuff implant for sciatic nerve stimulation in anesthetized mice. (Panel based on data in Llewellyn et al. 2010.) (D) Illustration of a micro LED implant for illumination of sciatic nerve endings in awake, freely moving mice. (Panel reprinted from Montgomery et al. 2016 with permission from The American Association for the Advancement of Science $\odot$ 2016.) (E) Illustration of a super soft, micro LED-based optoelectronic device for illumination of sensory nerve endings on the bladder in awake, freely moving mice. (Panel reprinted from Samineni et al. 2017a courtesy of Scientific Reports in conjunction with Creative Commons Licensing.)

\section{DIVERGENT VAGAL NEURON POPULATIONS AND OPTOGENETIC CONTROL OF AUTONOMIC PHYSIOLOGY}

The vagus nerve, the 10th cranial nerve, is a major conduit between body organs and brain that senses visceral changes and controls autonomic functions (Fig. 3). The vagus nerve innervates a variety of visceral organs, including the larynx, pharynx, trachea, lung, heart, aortic arch, stomach, intestine, liver, kidney, esophagus, intestine, and others (Berthoud and Neuhuber 2000; Yuan and Silberstein 2016b). Both ascending sensory afferent fibers and descending motor efferent fibers travel in the vagus nerve. Vagal sensory fibers, which comprise the majority 
R.B. Chang
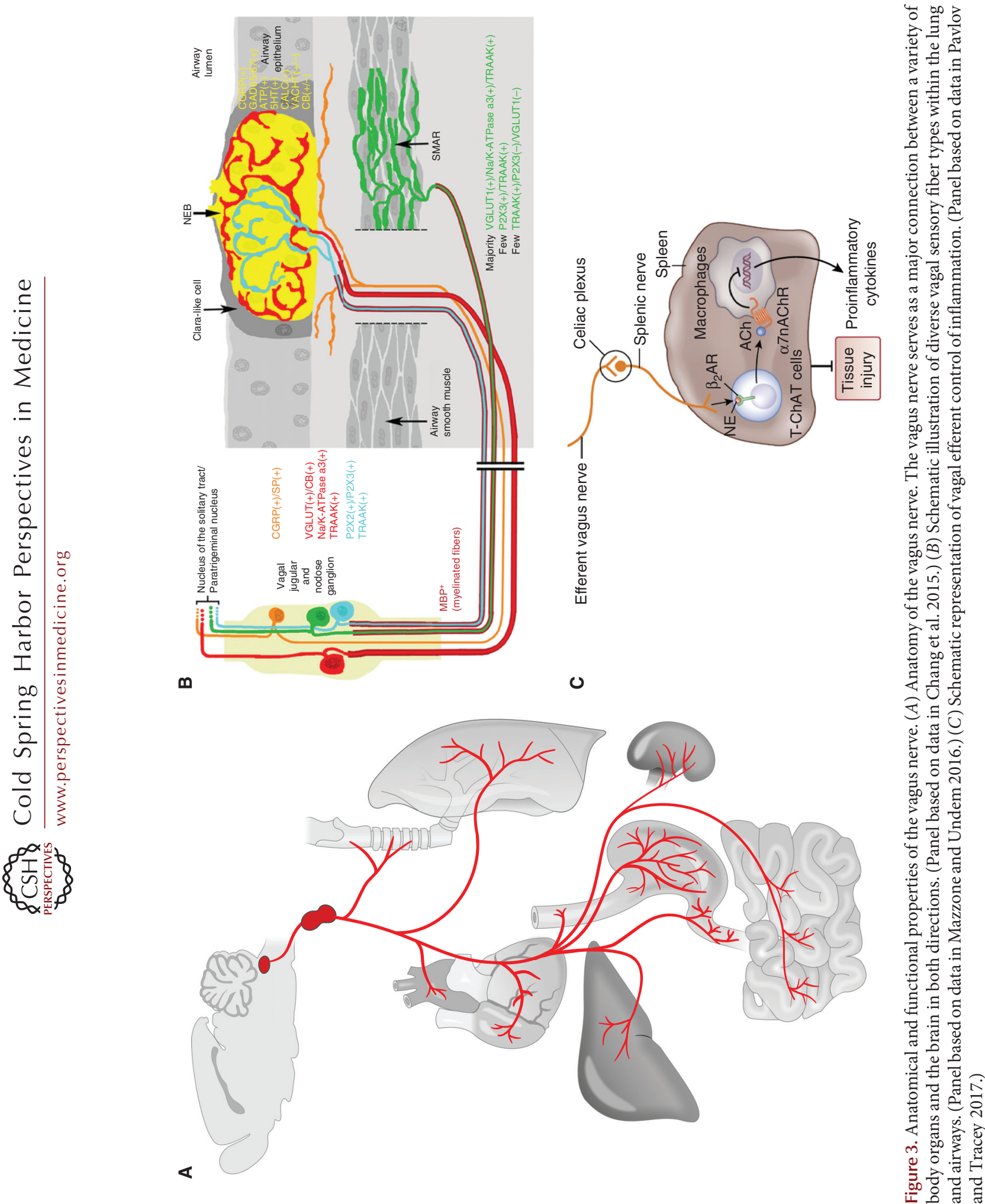
Optogenetic Control of Peripheral Nervous System

( $\sim 80 \%)$ of the vagus nerve (Foley and DuBois $1937)$, carry a variety of environmental, physiological, and pathological information from the periphery, including airway pressure changes, inhaled air contents, ingested substances, blood pressure fluctuations, mechanical stretches along the gastrointestinal tract, inflammatory cues, and many others (Paintal 1973). On the other hand, vagal motor fibers participate in the control of diverse visceral functions such as bronchoconstriction, heart regulation, pancreas enzyme secretion, gastrointestinal motility, and inflammatory responses via acetylcholine release. Cell bodies of vagal sensory neurons reside in a pair of ganglia named nodose and jugular ganglion near the jugular foramen, while cell bodies of vagal motor neurons are located within the dorsal motor nucleus of the vagus (DMV) and the nucleus ambiguus in the brainstem. Gross anatomy, response properties, and physiological functions of vagal neurons have been extensively studied using histological, electrophysiological, pharmacological, and surgical approaches for over a century, yet our knowledge about the coding logic and some basic principles by which the vagus nerve regulates diverse autonomic physiology is still poor, largely a result of a lack of appropriate tools, presenting a major challenge for a deeper understanding of the underlying molecular mechanisms. A variety of cellular analyses regarding expression patterns of neuropeptides, receptors, ion channels, transporters, and transcription factors in vagal neurons were carried out using immunocytochemistry, RNA in situ hybridization, and single-cell-based gene analysis to uncover neuron heterogeneity and to understand potential cell signaling pathways (Helke and Hill 1988; Zhuo et al. 1997; Chang et al. 2015; Sajgo et al. 2016; Wang et al. 2017). However, the link between previous anatomical and functional findings and such molecularly defined neuron populations is still largely missing. Recent studies employing state-of-the-art mouse genetic tools were shown to be powerful in dissecting these essential body-to-brain circuits (Sisley et al. 2014; Trankner et al. 2014; Chang et al. 2015; Williams et al. 2016; Nonomura et al. 2017; Baral et al. 2018; Han et al. 2018). Here we will review some initial work with optogenetics in the vagus nerve (Fig. 4) and discuss the potential future applications.

\section{Optogenetic Control of Breathing}

Breathing is an essential physiological function for animal survival, providing appropriate oxygen into the body and taking away the metabolic wastes such as carbon dioxide $\left(\mathrm{CO}_{2}\right)$. Breathing is tightly controlled by the nervous system. In particular, groups of neurons located in the medulla oblongata in the brainstem form respiratory centers responsible for respiratory rhythm generation and motor pattern formation. Such neurons receive numerous regulatory inputs from both peripheral and other brain regions to ensure a precise regulation of respiration for appropriate tissue oxygenation at all conditions (Ikeda et al. 2017). Environmental, physiological, and psychological factors, such as inhaled air content, blood oxygen, $\mathrm{CO}_{2}$, and $\mathrm{pH}$ levels, temperature, cardiovascular functions, circadian rhythm, mood, stress, and many others influence respiratory functions, including breathing frequency, depth, and pattern through a variety of mechanisms and neural pathways. Some essential respiratory reflexes involving mechanosensation along the respiratory tract and chemosensation from the lung, airways, and bloodstream are mediated by the vagal afferents (Paintal 1973; Widdicombe 2001; Mazzone and Undem 2016). Several classes of airway afferents were described (Fig. 3B; Widdicombe 2001; Carr and Undem 2003; Mazzone and Undem 2016). In general, airway mechanosensory fibers are myelinated fast-conducting A fibers that respond to airway inflation or deflation from diverse locations with different mechanosensitivities but not to capsaicin, a TRPV1 channel agonist commonly used to assess fiber chemosensitivity. Based on their response adaptation properties, airway mechanosensory fibers are further divided into rapidly adapting receptors (RARs) and slowly adapting receptors (SARs). Locations of RAR and SAR endings were determined using electrophysiology, yet their terminal structures were not precisely resolved. SARs are believed to mediate the 
R.B. Chang

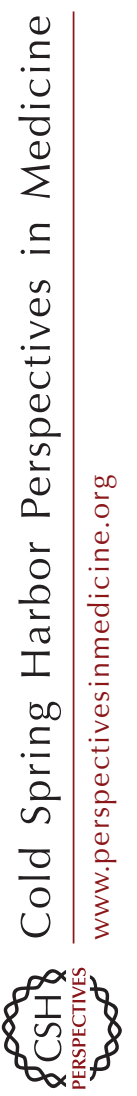

A

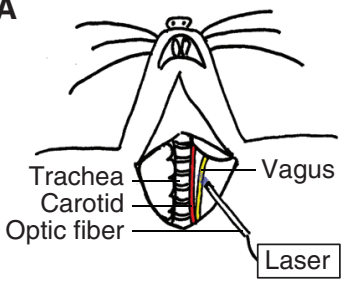

$B$

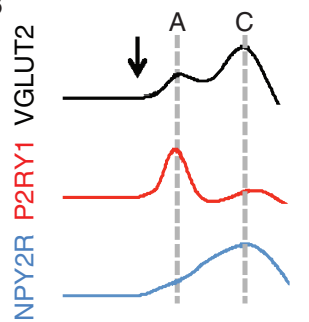

C

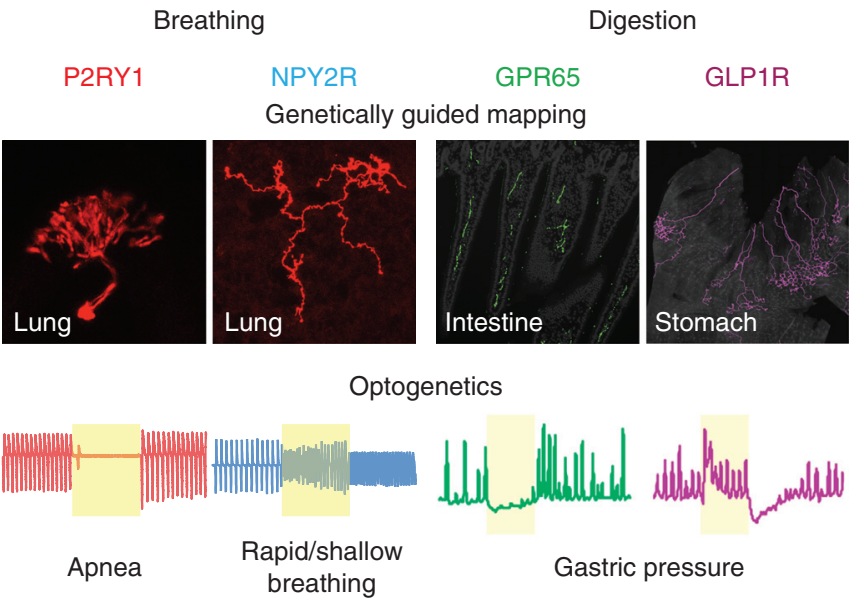

Figure 4. Optogenetic control of the vagus nerve in anesthetized mice. (A) Cartoon depiction of optogenetic stimulation of surgically exposed vagus nerve in anesthetized mice. (Panel from Chang et al. 2015; reprinted, with permission, from Elsevier $\odot$ 2015.) (B) Measurements of conduction velocity in genetically defined sensory neuron populations with optogenetics. Compound action potentials evoked by brief optogenetic stimulation indicated that a majority of vagal P2RY1 fibers are fast-conducting A fibers and NPY2R fibers are largely slowconducting C fibers. (Panel based on data in Chang et al. 2015.) (C) Summary of a few genetically defined vagal sensory neuron populations involved in control of respiration and digestion. (Panel based on data in Chang et al. 2015 and Williams et al. 2016.)

pulmonary stretch response, also named the Hering-Breuer reflex, which is an inhibitory respiratory reflex to lung inflation or deflation while RARs may mediate cough and other irritant responses, although their roles are still under debate. In contrast, airway chemosensory fibers are nonmyelinated, capsaicin-responsive, slow-conducting $\mathrm{C}$ fibers that mediate defensive respiratory responses such as rapid and shallow breathing. Although extensively investigated, a major challenge in understanding the respiratory reflexes is the lack of tools to selectively target particular fiber populations in intact or awake animals. It has been difficult to associate fiber types defined by electrophysiology with anatomical findings and physiological studies.

Recent application of genetic tools to the vagus nerve may help eventually overcome this problem (Chang et al. 2015; Nonomura et al. 2017). Using transgenic mouse models based on Cre-LoxP technology, diverse vagal subpopulations were genetically targeted and their projection patterns, neuronal response properties, and physiological roles were assessed. In partic- ular, the feasibility of applying optogenetics in the vagus nerve to control autonomic physiology, such as breathing, was demonstrated in these studies. ChR2 (H134R) was introduced to genetically targeted vagal sensory neuron populations by crossing Cre mice with reporter mice carrying a Cre-dependent ChR2 H134R allele (lox-ChR2 mice, Jackson Lab Stock \#024109) to obtain driver-Cre; lox-ChR2 mice. For example, to express ChR2 (H134R) in all vagal sensory but not vagal moter neurons, Vglut2ires-Cre, which selectively target vagal sensory neurons, were used to obtain Vglut2-ires-Cre; lox-ChR2 mice. Blue light generated from a 473-nm DPSS laser was delivered to the vagus nerve through a 200 - to $400-\mu \mathrm{m}$ optic fiber precisely placed on top of the carefully dissected vagus nerve or vagal ganglia using a micromanipulator in anesthetized animals (Fig. 4). Light intensity was adjusted to $75-125 \mathrm{~mW} / \mathrm{mm}^{2}$ to achieve optimized activation without causing thermal side effects. Stimulation frequency and duration was controlled using an optical shutter that physically blocks the light beam. Robust 
neuronal activation was observed in the vagus nerve in response to blue light stimulation in these animals, as revealed by whole nerve electrophysiology, suggesting in vivo optogenetic stimulation was successful. High-frequency stimulation $(5 \mathrm{msec}, 50 \mathrm{~Hz}$ ) of all vagal sensory neurons using Vglut2-ires-Cre; lox-ChR2 mice caused an acute apnea, followed by a second phase of rapid and shallow breathing over a 10 -sec trial. This effect was not observed in control animals that either lack the Cre driver or the ChR2 reporter, or in Chat-ires-Cre; lox-ChR2 mice in which ChR2 is expressed in vagal motor neurons, suggesting that the light-evoked response requires functional $\mathrm{ChR} 2$ in the sensory arm of the vagus nerve. Interestingly, this effect was not obvious when using lower frequency stimulation ( $5 \mathrm{msec}, 5 \mathrm{~Hz}$ ), consistent with previous findings that physiological responses triggered by VNS is frequency dependent.

Optogenetic stimulation of two distinct vagal sensory neuron populations elicited powerful but opposite respiratory responses. Activating vagal P2RY1 neurons using P2ry1-ires-Cre; lox-ChR2 mice resulted in a similar respiratory pause without the second phase observed when all sensory neurons were stimulated, while activating NPY2R neurons in Npy2r-ires-Cre; loxChR2 mice elicited rapid and shallow breathing. Not all vagal neuron types contribute to breathing, as activating vagal GPR65 neurons had no effect on respiratory patterns. Anatomical studies further confirmed that both vagal P2RY1 and NPY2R but not GPR65 neurons project extensively to the lung. Intriguingly, vagal P2RY1 and NPY2R neurons have different pulmonary arborization patterns and terminal morphologies. P2RY1 neurons account for the majority of vagal afferent fibers innervating the neuroepithelial bodies, while NPY2R fibers are enriched near the alveoli in the lung respiratory zone. This morphological difference suggests that they may be involved in distinct respiratory reflexes, and may provide an essential anatomical basis for understanding the underlying sensory mechanisms.

Conduction velocity is a widely used parameter to assess the electrophysiological property of peripheral nerve fibers, including vagal afferents. To determine electrical properties of genetically defined vagal neuron types, an optogenetics-assisted approach was developed. Instead of using a pair of wires for electrical stimulation, an optic fiber was used for ultrafast (0.8 msec) optogenetic stimulation (Fig. 4), and propagation speed was calculated by varying the distance between the optic fiber and recording electrodes. Both characteristics of $\mathrm{A}$ and $\mathrm{C}$ fiber responses were observed when all vagal sensory neurons are stimulated in Vglut2-ires-Cre; lox-ChR2 mice, with an A/C ratio around 0.6, consistent with previous findings that the majority of vagal afferents are C fibers. Similar studies further demonstrated that the majority of vagal P2RY1 neurons are fast-conducting A fibers, while most NPY2R neurons are slowconducting $\mathrm{C}$ fibers.

Intriguingly, a subset of vagal P2RY1 neurons coexpresses Piezo2, the mechanoreceptor essential for gentle touch and proprioception. Optogenetic stimulation of vagal Piezo2 neurons similarly caused apnea, suggesting that they may detect mechanical signals from the lung (Nonomura et al. 2017). Indeed, when Piezo2 was conditionally deleted from vagal sensory neurons using Phox $2 b$-Cre, lung inflationinduced vagus nerve activation was abolished and the Hering-Breuer reflex was diminished, providing for the first time a molecular mechanism for pulmonary stretch detection.

\section{Optogenetic Control of Gastrointestinal Functions}

Organs along the gastrointestinal tract, including esophagus, stomach, and intestine are highly coordinated to achieve efficient food digestion and nutrient absorption (Cummings and Overduin 2007). Gastrointestinal organs also play a defensive role in preventing absorption of noxious or toxic substances by inducing vomiting or diarrhea (Horn 2014). Ingested food contents and mechanical stretch along the gastrointestinal tract are important sensory cues for appropriate regulation of digestive functions and feeding behaviors. Gastrointestinal organs are densely innervated by vagal sensory nerves (Paintal 1973; Fox et al. 2000; Berthoud et al. 
2004). Similar to vagal airway afferents, sensory fibers that project to the gastrointestinal tract are largely mechanosensitive or chemosensitive. Mechanosensory afferents form specialized terminal structures such as intraganglionic laminar endings and intramuscular arrays on the muscular wall of the esophagus, stomach, and small intestine to detect stretch along the gastrointestinal tract, whereas mucosal endings likely sense ingested or digested substances from the digestive tract indirectly. Neural circuits between vagal sensory and motor fibers, so-called vago-vagal reflexes, are important for coordinating gastrointestinal motility and regulation of enzyme secretion after food ingestion (Rogers et al. 1995). Yet, the underlying neural architectures and molecular mechanisms are not well understood.

Vagal afferents likely detect nutrients from multiple locations along the gastrointestinal tract (Maljaars et al. 2008). Within the proximal small intestine, food contents do not contact vagal sensory endings directly but instead are detected by enteroendocrine cells or enterochromaffin cells, specialized epithelial cells on the intestinal villi that release a myriad of gut-derived signals, including glucagon-like peptide 1 (GLP1), peptide YY, cholecystokinin, and serotonin to regulate digestive processes like acid secretion and stomach contractility, as well as feeding behaviors (Chambers et al. 2013; Kim et al. 2018). The sensory vagus nerve is involved in a variety of gastrointestinal reflexes; however, the underlying sensory mechanisms are under debate. As vagal afferents innervating small intestinal villi terminate close to enteroendocrine and enterochromaffin cells and receptors for many gut-derived peptides are expressed in vagal sensory neurons, it is commonly assumed that gut signals released from enteroendocrine and enterochromaffin cells bind to their receptors at peripheral afferent terminals to initiate signal transduction. GLP-1 is one gut hormone proposed to mediate aspects of nutrient detection by the vagus nerve, such as food intake, gastric emptying, and glycemia (Krieger et al. 2016). However, genetic deletion of its receptor GLP1R from vagal afferents did not impact GLP-1 agonist-induced changes in body weight and glucose homeostasis (Sisley et al. 2014), challenging the role of vagal GLP1R in digestion and feeding behavior. Moreover, vagal GLP1R neurons displayed minimum projection to intestinal villi but densely innervated the muscular layer of stomach and small intestine, as revealed by AAV-guided anatomical tracing in Glp1rires-cre mice (Williams et al. 2016). Consistently, vagal GLP1R neurons accounted for the vast majority of stretch sensations from stomach and small intestine, yet vagal neurons that responded to intestinal nutrients were largely GLP1R negative. Through an optogenetics-based screening performed to identify vagal sensory neuron populations that regulate gastric contractility, vagal GPR65 neurons were discovered as a potent inhibitor of gastric contractions (Williams et al. 2016). In this study, ChR2 was similarly expressed in selective vagal neuron populations using diverse Cre lines harboring a Cre-dependent ChR2 allele, and light delivery was achieved through an optic fiber positioned next to the vagus nerve or vagal ganglia. Gastric contractility was measured as intragastric pressure changes using a pressure transducer cannulated into the stomach. Optogenetic stimulation was similarly performed as aforementioned, using a low stimulation frequency ( $5 \mathrm{msec}, 5 \mathrm{~Hz}$ ), which was efficient for gastric responses without causing drastic respiratory or heart rate changes. Optogenetic activation of vagal GPR65 neurons potently reduced stomach contractions, as revealed by intraluminal gastric pressure measurements. Moreover, anatomical and calcium imaging data indicated that vagal GPR65 neurons account for the majority of vagal afferents that detect food from the intestinal villi. Such results provided a new and proper neural target for understanding the communication between intestinal epithelial cells and the sensory vagus nerve regarding nutrient sensation. The exact role of GLP1R in the sensory vagus nerve still needs to be elucidated, and such genetic data supports an alternative model that at least some gut hormones released in response to ingested food may regulate gastrointestinal functions through modulating gastrointestinal mechanoreceptors.

Vagus nerve controls a variety of essential autonomic functions. In addition, VNS is an 
FDA-approved treatment for patients with epilepsy, recurrent depression, clustered headache, and migraine pain (Schachter and Saper 1998; Rush et al. 2000; Uthman 2000; Groves and Brown 2005; O’Reardon et al. 2006; Krahl 2012; Yuan and Silberstein 2016a; Siefring 2017; Brauser 2018). However, deeper mechanistic understanding of autonomic regulation and better therapeutic specificity and efficacy are hindered because of the lack of appropriate cell-type-specific neuromodulation tools, calling for the development of new approaches. Optogenetics provides a powerful cell-specific modulatory approach for precise dissection of the physically intermingled but functionally distinct vagal fiber types. So far, most studies regarding optogenetic control of autonomic physiology via the vagus nerve has been limited to anesthetized animals. Because of technical challenges for light delivery, optogenetic control of vagal fibers in awake, freely moving animals has been difficult, which prevents a variety of essential physiological and behavioral studies. Many fascinating questions remain to be answered. Are vagal P2RY1 or NPY2R neurons involved in cough or asthma? Do vagal GPR65 neurons also regulate food intake? What is the designated neuron population for inflammation control? Which neurons are responsible for the effects of VNS on epilepsy and depression? In general, there are two ways to deliver light to awake, freely behaving animals: internal or transdermal light illumination. Both approaches have been explored in the PNS and could be potentially applied to the vagus nerve. Surgically implanted optical cuffs and LED arrays were designed to illuminate peripheral nerves deep inside the body and transdermal light stimulation has been widely used to illuminate nerve terminals on the skin in pain studies. A few examples will be summarized in the following sections.

\section{OPTOGENETIC CONTROL OF THE PERIPHERAL NERVOUS SYSTEM IN AWAKE, FREELY BEHAVING ANIMALS}

One of the best applications for transdermal light illumination is optogenetic modulation of sensory fibers that terminate on the skin. In transgenic animals in which ChR2 is expressed in DRG neuron populations either under specific promotors or delivered by viral infections, transdermal blue light-induced changes, including paw withdrawal and other pain-like behaviors and long-term sensitization to mechanical and thermal stimuli, were observed (Ji et al. 2012; Daou et al. 2013; Boada et al. 2014; Draxler et al. 2014; Iyer et al. 2014). Conversely, when inhibitory opsins were expressed in skin-innervating DRG neurons, transdermal illumination with green or yellow light reduced pain behaviors (Boada et al. 2014; Iyer et al. 2014; Daou et al. 2016). When ChR2 was expressed in intrinsic and extrinsic whisker pad muscles, blue light stimulation on the whisker pad caused whisker movements (Park et al. 2016). On the other hand, for nerve fibers located deeper inside the body, noninvasive neuromodulation with transdermal light illumination becomes much less efficient. One possible solution is to increase the opsin expression level to compensate for the light loss. As revealed in a recent study (Maimon et al. 2017), when motor neurons are retrogradely infected with an ultraconcentrated ChR2 virus, transdermal blue light stimulation were sufficient to elicit muscle movements. Moreover, ankle positions can be accurately controlled by light stimulation. However, it is unlikely to adapt this approach to nerves deeper in visceral organs as the penetration depth of blue light in skin tissue is around 2 mm (Avci et al. 2013; Ash et al. 2017). Longer wavelength light can reach deeper tissues. For example, red light can penetrate $5 \mathrm{~mm}$ into the skin. Other factors that will influence light penetration in tissues are scattering and absorption. Therefore, another strategy extensively explored is to use longer wavelength light and red-shifted opsins to achieve neuromodulation in nerves deeper in the body. For example, a flexible red OLED device was developed for transdermal optogenetic vagal stimulation (Smith et al. 2016), yet its in vivo application needs to be further determined.

Unlike light illumination onto neural targets on the skin or inside the brain, precise illumination of peripheral nerves deep inside the body with an implanted light source is quite challeng- 
ing because of tremendous displacement during animal movement. The main issue comes from nerve damage when using conventional lasercoupled fiberoptic nerve cuffs. Super flexible cuffs constructed using biocompatible organic polymer and small diameter optic fiber at a well-designed angle were developed to control large peripheral nerves deep inside the body (Towne et al. 2013). Sciatic nerve, one of the largest nerves in an animal, has been successfully targeted using such optical cuffs in rats. When ChR2 was expressed in sciatic motor neurons using retrograde AAV infection, light illumination through an optical cuff surgically placed around the sciatic nerve resulted in fine control of muscle movement. Successful control of hindlimb muscle contraction using similar soft optical cuffs placed on the sciatic nerve has also been demonstrated in mice (Michoud et al. 2018). However, application of optical cuffs is so far still limited to large peripheral nerves like the sciatic nerve in rodents. The development of smaller and softer optical cuffs in the future may facilitate the application to other smaller peripheral nerves including the vagus nerve.

Recent advances in LED technologies provided a powerful alternative for light delivery. Compared to lasers, miniature high-powered LEDs have several advantages that make them ideal for in vivo light delivery in awake, freely moving animals. First, to ensure enough light illumination, optic fibers with a certain diameter and stiffness have to be used while LED arrays could be more flexible. Second, it is hard to illuminate a large surface area with implanted optic fibers while LED arrays can be designed to wrap around a whole organ. Third, animals have to be tethered with an optic fiber when using a laser, while LED arrays can be wirelessly controlled (Wentz et al. 2011; Kim et al. 2013; Yeh et al. 2013; Rossi et al. 2015; Samineni et al. 2017b), which enables truly freely moving studies. On the other hand, as light emitted from LEDs are not coherent, tissue penetration may not be as good, and thermal- induced side effects should always be considered and examined. An LED array-based optical cuff was demonstrated in 2010 to be effective in precise control of muscle movement when placed around the sciatic nerve in anesthetized Thy1-ChR2 mice (Llewellyn et al. 2010). This effect was similarly achieved using a wireless LED-based optical cuff a few years later (Kang-Il et al. 2015). A variety of LED devices were thereafter designed and applied for optogenetic modulation of peripheral nerves in awake, freely moving animals. For example, in mice in which ChR2 was expressed in sciatic nociceptive neurons, nociceptive behaviors were elicited using a wireless LED stimulation device implanted subcutaneously near the sciatic nerve endings in the hind paw (Montgomery et al. 2015). Using a miniaturized stretchable $\mu$-LED-based wireless optoelectronic system placed around the sciatic nerve, nociceptive behaviors were also successfully elicited in Advillin-ChR2 and TRPV1-ChR2 mice (Park et al. 2015). Such wireless $\mu$-LED arrays can be designed to cover a large surface area. For example, using a green LED mesh placed around the bladder in SNS-Arch-GFP mice, genetically targeted nociceptive afferents that innervate the bladder were silenced in vivo, and induced bladder pain was reduced in awake, freely behaving animals (Samineni et al. 2017a).

\section{OTHER GENETIC NEUROMODULATORY APPROACHES AND POTENTIAL THERAPEUTIC APPLICATIONS}

Some of the recent neuromodulatory applications based on optogenetics are summarized here. While there are numerous advantages of using microbial opsins and optogenetics to modulate neural activity over conventional methods, including genetic access and precise spatial and temporal control, light delivery can be difficult to achieve especially for many peripheral nerves and surgical implantation is usually required. Moreover, although wireless LED devices are gaining increasing attention, laser or LED-coupled optic fiber implants are still used in most cases, meaning that animals are tethered and not completely free-moving. Chemical-based chemogenetic approaches involving designer receptors exclusively activated by designer drugs (so-called DREADDs) provide a great alternative for cell-type-specific 
neuromodulation (Urban and Roth 2015). Compared to optogenetic methods, DREADDs render the capability of simple chronic neuromodulation in untethered animals. With i.p. injection or oral administration of DREADDspecific ligands, long-lasting neuronal activation/silencing can be easily achieved for $6-8 \mathrm{~h}$. In the PNS, DREADDs-based chemogenetic approaches were widely used to control pain and nociceptive behaviors.

So far, cell-type-specific neuromodulatory approaches have greatly advanced our understanding of the PNS in animal studies, and the potential of using optogenetics and chemogenetics to treat or alleviate chronic pain and motor disorders has been demonstrated using rodent disease models. More attentions have been drawn to their potential therapeutic applications in human patients. One major challenge in human therapy is to safely, effectively, and stably express opsins or DREADDs in target cell populations. Recent advances in virus development have enabled such genetic neuromodulatory approaches in nonhuman primates (Gerits and Vanduffel 2013). As the first AAVbased gene therapy, Luxturna, was approved by the FDA in December 2017, it is reasonable to believe that this challenge will be overcome in the near future.

\section{REFERENCES}

Ardell JL, Nier H, Hammer M, Southerland EM, Ardell CL, Beaumont E, KenKnight BH, Armour JA. 2017. Defining the neural fulcrum for chronic vagus nerve stimulation: Implications for integrated cardiac control. J Physiol 595: 6887-6903. doi:10.1113/JP274678

Arenkiel BR, Peca J, Davison IG, Feliciano C, Deisseroth K, Augustine GJ, Ehlers MD, Feng G. 2007. In vivo lightinduced activation of neural circuitry in transgenic mice expressing channelrhodopsin-2. Neuron 54: 205-218. doi:10.1016/j.neuron.2007.03.005

Armour JA, Murphy DA, Yuan BX, Macdonald S, Hopkins DA. 1997. Gross and microscopic anatomy of the human intrinsic cardiac nervous system. Anat Rec 247: 289-298. doi:10.1002/(SICI)1097-0185(199702)247:2<289::AIDAR15>3.0.CO;2-L

Ash C, Dubec M, Donne K, Bashford T. 2017. Effect of wavelength and beam width on penetration in light-tissue interaction using computational methods. Lasers Med Sci 32: 1909-1918. doi:10.1007/s10103-017-2317-4

Avci P, Gupta A, Sadasivam M, Vecchio D, Pam Z, Pam N, Hamblin MR. 2013. Low-level laser (light) therapy
(LLLT) in skin: Stimulating, healing, restoring. Semin Cutan Med Surg 32: 41-52.

Baral P, Umans BD, Li L, Wallrapp A, Bist M, Kirschbaum T, Wei Y, Zhou Y, Kuchroo VK, Burkett PR, et al. 2018. Nociceptor sensory neurons suppress neutrophil and $\gamma \delta$ $\mathrm{T}$ cell responses in bacterial lung infections and lethal pneumonia. Nat Med 24: 417-426. doi:10.1038/nm.4501

Berglund K, Clissold K, Li HE, Wen L, Park SY, Gleixner J, Klein ME, Lu D, Barter JW, Rossi MA, et al. 2016. Luminopsins integrate opto- and chemogenetics by using physical and biological light sources for opsin activation. Proc Natl Acad Sci 113: E358-E367. doi:10.1073/pnas. 1510899113

Berthoud HR, Neuhuber WL. 2000. Functional and chemical anatomy of the afferent vagal system. Auton Neurosci 85: 1-17. doi:10.1016/S1566-0702(00)00215-0

Berthoud HR, Blackshaw LA, Brookes SJ, Grundy D. 2004 Neuroanatomy of extrinsic afferents supplying the gastrointestinal tract. Neurogastroenterol Motil 16(Suppl. 1): 28-33. doi:10.1111/j.1743-3150.2004.00471.x

Boada MD, Martin TJ, Peters CM, Hayashida K, Harris MH, Houle TT, Boyden ES, Eisenach JC, Ririe DG. 2014. Fastconducting mechanoreceptors contribute to withdrawal behavior in normal and nerve injured rats. Pain 155: 2646-2655. doi:10.1016/j.pain.2014.09.030

Bonaz B. 2018. Is there a place for vagus nerve stimulation in inflammatory bowel diseases? Bioelectron Med 4. doi:10.1186/s42234-018-0004-9

Boyden ES. 2011. A history of optogenetics: The development of tools for controlling brain circuits with light. F1000 Biol Rep 3: 11. doi:10.3410/B3-11

Boyden ES, Zhang F, Bamberg E, Nagel G, Deisseroth K. 2005. Millisecond-timescale, genetically targeted optical control of neural activity. Nat Neurosci 8: 1263-1268. doi: 10.1038/nn1525

Brauser D. 2018. FDA clears vagus nerve stimulator for migraine pain. Medscape, https://www.medscape.com/ viewarticle/891930.

Carr MJ, Undem BJ. 2003. Bronchopulmonary afferent nerves. Respirology 8: 291-301. doi:10.1046/j.14401843.2003.00473.x

Catala M, Kubis N. 2013. Gross anatomy and development of the peripheral nervous system. Handb Clin Neurol 115: 29-41. doi:10.1016/B978-0-444-52902-2.00003-5

Cerfolio RJ, De Campos JR, Bryant AS, Connery CP, Miller DL, DeCamp MM, McKenna RJ, Krasna MJ. 2011. The Society of Thoracic Surgeons expert consensus for the surgical treatment of hyperhidrosis. Ann Thorac Surg 91: 1642-1648. doi:10.1016/j.athoracsur.2011.01.105

Chambers AP, Sandoval DA, Seeley RJ. 2013. Integration of satiety signals by the central nervous system. Curr Biol 23: R379-R388. doi:10.1016/j.cub.2013.03.020

Chang RB, Strochlic DE, Williams EK, Umans BD, Liberles SD. 2015. Vagal sensory neuron subtypes that differentially control breathing. Cell 161: 622-633. doi:10.1016/j. cell.2015.03.022

Chapleau MW, Rotella DL, Reho JJ, Rahmouni K, Stauss HM. 2016. Chronic vagal nerve stimulation prevents high-salt diet-induced endothelial dysfunction and aortic stiffening in stroke-prone spontaneously hypertensive 
R.B. Chang

rats. Am J Physiol Heart Circ Physiol 311: H276-H285. doi:10.1152/ajpheart.00043.2016

Chow BY, Han X, Dobry AS, Qian X, Chuong AS, Li M, Henninger MA, Belfort GM, Lin Y, Monahan PE, et al. 2010. High-performance genetically targetable optical neural silencing by light-driven proton pumps. Nature 463: 98-102. doi: $10.1038 /$ nature 08652

Costa M, Brookes SJ, Hennig GW. 2000. Anatomy and physiology of the enteric nervous system. Gut $\mathbf{4 7}$ (Suppl 4): iv15-iv19; discussion iv26.

Cummings DE, Overduin J. 2007. Gastrointestinal regulation of food intake. J Clin Invest 117: 13-23. doi:10.1172/ JCI30227

Daou I, Tuttle AH, Longo G, Wieskopf JS, Bonin RP, Ase AR, Wood JN, De Koninck Y, Ribeiro-da-Silva A, Mogil JS, et al. 2013. Remote optogenetic activation and sensitization of pain pathways in freely moving mice. J Neurosci 33: 18631-18640. doi:10.1523/jneurosci.2424-13.2013

Daou I, Beaudry H, Ase AR, Wieskopf JS, Ribeiro-daSilva A, Mogil JS, Seguela P. 2016. Optogenetic silencing of Nav1.8-positive afferents alleviates inflammatory and neuropathic pain. eNeuro 3. doi:10.1523/eneuro.014015.2016

Das UN. 2011. Vagus nerve stimulation as a strategy to prevent and manage metabolic syndrome. Med Hypotheses 76: 429-433. doi:10.1016/j.mehy.2010.11.013

De Ferrari GM, Stolen C, Tuinenburg AE, Wright DJ, Brugada J, Butter C, Klein H, Neuzil P, Botman C, Castel MA et al. 2017. Long-term vagal stimulation for heart failure: Eighteen month results from the NEural Cardiac TherApy foR Heart Failure (NECTAR-HF) trial. Int J Cardiol 244: 229-234. doi:10.1016/j.ijcard.2017.06.036

Deisseroth K. 2015. Optogenetics: 10 years of microbial opsins in neuroscience. Nat Neurosci 18: 1213-1225. doi:10.1038/nn.4091

de Lartigue G. 2014. Putative roles of neuropeptides in vagal afferent signaling. Physiol Behav 136: 155-169. doi:10.1016/j.physbeh.2014.03.011

DiCarlo LA, Libbus I, Kumar HU, Mittal S, Premchand RK, Amurthur B, KenKnight BH, Ardell JL, Anand IS. 2018. Autonomic regulation therapy to enhance myocardial function in heart failure patients: The ANTHEM-HFpEF study. ESC Heart Fail 5: 95-100. doi:10.1002/ehf2.12241

Draxler P, Honsek SD, Forsthuber L, Hadschieff V, Sandkuhler J. 2014. VGluT3 ${ }^{+}$primary afferents play distinct roles in mechanical and cold hypersensitivity depending on pain etiology. J Neurosci 34: 12015-12028. doi:10. 1523/jneurosci.2157-14.2014

Drott C. 1994. The history of cervicothoracic sympathectomy. Eur J Surg Suppl 572: 5-7.

Foley JO, DuBois FS. 1937. Quantitative studies of the vagus nerve in the cat. I: The ratio of sensory to motor fibers. J Comp Neurol 67: 49-67. doi:10.1002/cne.900670104

Fox EA, Phillips RJ, Martinson FA, Baronowsky EA, Powley TL. 2000. Vagal afferent innervation of smooth muscle in the stomach and duodenum of the mouse: morphology and topography. J Comp Neurol 428: 558576. doi:10.1002/1096-9861(20001218)428:3<558::AIDCNE11>3.0.CO;2-M
Furness JB. 2012. The enteric nervous system and neurogastroenterology. Nat Rev Gastroenterol Hepatol 9: 286-294. doi:10.1038/nrgastro.2012.32

Gerits A, Vanduffel W. 2013. Optogenetics in primates: A shining future? Trends Genet 29: 403-411. doi:10.1016/j. tig.2013.03.004

Gold MR, Van Veldhuisen DJ, Hauptman PJ, Borggrefe M, Kubo SH, Lieberman RA, Milasinovic G, Berman BJ Djordjevic S, Neelagaru S, et al. 2016. Vagus nerve stimulation for the treatment of heart failure: The INOVATEHF trial. J Am Coll Cardiol 68: 149-158. doi:10.1016/j. jacc.2016.03.525

Goto T, Iwai H, Kuramoto E, Yamanaka A. 2017. Neuropeptides and ATP signaling in the trigeminal ganglion. Jpn Dent Sci Rev 53: 117-124. doi:10.1016/j.jdsr.2017.01.003

Gradinaru V, Thompson KR, Deisseroth K. 2008. eNpHR: A Natronomonas halorhodopsin enhanced for optogenetic applications. Brain Cell Biol 36: 129-139. doi:10.1007/ s11068-008-9027-6

Groves DA, Brown VJ. 2005. Vagal nerve stimulation: A review of its applications and potential mechanisms that mediate its clinical effects. Neurosci Biobehav Rev 29: 493-500. doi:10.1016/j.neubiorev.2005.01.004

Habib N, Avraham-Davidi I, Basu A, Burks T, Shekhar K, Hofree M, Choudhury SR, Aguet F, Gelfand E, Ardlie K, et al. 2017. Massively parallel single-nucleus RNA-seq with DroNc-seq. Nat Methods 14: 955-958. doi:10. 1038/nmeth. 4407

Han X, Boyden ES. 2007. Multiple-color optical activation, silencing, and desynchronization of neural activity, with single-spike temporal resolution. PLoS ONE 2: e299. doi: 10.1371/journal.pone.0000299

Han L, Limjunyawong N, Ru F, Li Z, Hall OJ, Steele H, Zhu Y, Wilson J, Mitzner W, Kollarik M, et al. 2018. Mrgprs on vagal sensory neurons contribute to bronchoconstriction and airway hyper-responsiveness. Nat Neurosci 21: 324-328. doi:10.1038/s41593-018-0074-8

Helke CJ, Hill KM. 1988. Immunohistochemical study of neuropeptides in vagal and glossopharyngeal afferent neurons in the rat. Neuroscience 26: 539-551. doi:10. 1016/0306-4522(88)90166-2

Hoffmann TJ, Simon BJ, Zhang Y, Emala CW. 2012. Low voltage vagal nerve stimulation reduces bronchoconstriction in guinea pigs through catecholamine release. Neuromodulation 15: 527-536. doi:10.1111/j.15251403.2012.00454.x

Horn CC. 2014. The medical implications of gastrointestinal vagal afferent pathways in nausea and vomiting. Curr Pharm Des 20: 2703-2712. doi:10.2174/13816128 113199990568

Ikeda K, Kawakami K, Onimaru H, Okada Y, Yokota S, Koshiya N, Oku Y, Iizuka M, Koizumi H. 2017. The respiratory control mechanisms in the brainstem and spinal cord: Integrative views of the neuroanatomy and neurophysiology. J Physiol Sci 67: 45-62. doi:10.1007/s12576016-0475-y

Inoue T, Abe C, Sung SS, Moscalu S, Jankowski J, Huang L, Ye H, Rosin DL, Guyenet PG, Okusa MD. 2016. Vagus nerve stimulation mediates protection from kidney ischemia-reperfusion injury through $\alpha 7 \mathrm{nAChR}^{+}$splenocytes. J Clin Invest 126: 1939-1952. doi:10.1172/JCI83658 
Iyer SM, Montgomery KL, Towne C, Lee SY, Ramakrishnan C, Deisseroth K, Delp SL. 2014. Virally mediated optogenetic excitation and inhibition of pain in freely moving nontransgenic mice. Nat Biotechnol 32: 274-278. doi:10.1038/nbt.2834

Jeon Y. 2016. Therapeutic potential of stellate ganglion block in orofacial pain: A mini review. J Dent Anesth Pain Med 16: 159-163. doi:10.17245/jdapm.2016.16.3.159

Ji ZG, Ito S, Honjoh T, Ohta H, Ishizuka T, Fukazawa Y, Yawo H. 2012. Light-evoked somatosensory perception of transgenic rats that express channelrhodopsin-2 in dorsal root ganglion cells. PLoS ONE 7: e32699. doi:10.1371/ journal.pone.0032699

Kang-Il S, Park SE, Myoung-Soo K, Chulmin J, Yong-Jun K, Suh JK, Dosik H, Inchan Y. 2015. An implantable wireless optogenetic stimulation system for peripheral nerve control. Conf Proc IEEE Eng Med Biol Soc 2015: 1033-1036.

Karemaker JM. 2017. An introduction into autonomic nervous function. Physiol Meas 38: R89-R118. doi:10.1088/ 1361-6579/aa6782

Kim TI, McCall JG, Jung YH, Huang X, Siuda ER, Li Y, Song J, Song YM, Pao HA, Kim RH, et al. 2013. Injectable, cellular-scale optoelectronics with applications for wireless optogenetics. Science 340: 211-216. doi:10.1126/ science. 1232437

Kim KS, Seeley RJ, Sandoval DA. 2018. Signalling from the periphery to the brain that regulates energy homeostasis. Nat Rev Neurosci 19: 185-196. doi:10.1038/nrn.2018.8

Klapoetke NC, Murata Y, Kim SS, Pulver SR, Birdsey-Benson A, Cho YK, Morimoto TK, Chuong AS, Carpenter EJ, Tian Z, et al. 2014. Independent optical excitation of distinct neural populations. Nat Methods 11: 338-346. doi:10.1038/nmeth.2836

Koopman FA, Chavan SS, Miliko S, Grazio S, Sokolovic S, Schuurman PR, Mehta AD, Levine YA, Faltys M, Zitnik $\mathrm{R}$, et al. 2016. Vagus nerve stimulation inhibits cytokine production and attenuates disease severity in rheumatoid arthritis. Proc Natl Acad Sci 113: 8284-8289. doi:10.1073/ pnas. 1605635113

Krahl SE. 2012. Vagus nerve stimulation for epilepsy: A review of the peripheral mechanisms. Surg Neurol Int 3: S47-S52. doi:10.4103/2152-7806.91610

Krieger JP, Arnold M, Pettersen KG, Lossel P, Langhans W, Lee SJ. 2016. Knockdown of GLP-1 receptors in vagal afferents affects normal food intake and glycemia. Diabetes 65: 34-43.

Land BB, Brayton CE, Furman KE, Lapalombara Z, Dileone RJ. 2014. Optogenetic inhibition of neurons by internal light production. Front Behav Neurosci 8: 108.

Levine JD, Fields HL, Basbaum AI. 1993. Peptides and the primary afferent nociceptor. J Neurosci 13: 2273-2286. doi:10.1523/jneurosci.13-06-02273.1993

Li X, Gutierrez DV, Hanson MG, Han J, Mark MD, Chiel H, Hegemann P, Landmesser LT, Herlitze S. 2005. Fast noninvasive activation and inhibition of neural and network activity by vertebrate rhodopsin and green algae channelrhodopsin. Proc Natl Acad Sci 102: 17816-17821. doi:10.1073/pnas.0509030102

Lin JY, Knutsen PM, Muller A, Kleinfeld D, Tsien RY. 2013. ReaChR: A red-shifted variant of channelrhodopsin enables deep transcranial optogenetic excitation. Nat Neurosci 16: 1499-1508. doi:10.1038/nn.3502
Lipof T, Shapiro D, Kozol RA. 2006. Surgical perspectives in peptic ulcer disease and gastritis. World J Gastroenterol 12: 3248-3252. doi:10.3748/wjg.v12.i20.3248

Llewellyn ME, Thompson KR, Deisseroth K, Delp SL. 2010. Orderly recruitment of motor units under optical control in vivo. Nat Med 16: 1161-1165. doi:10.1038/nm.2228

Macosko EZ, Basu A, Satija R, Nemesh J, Shekhar K, Goldman M, Tirosh I, Bialas AR, Kamitaki N, Martersteck EM, et al. 2015. Highly parallel genome-wide expression profiling of individual cells using nanoliter droplets. Cell 161: 1202-1214. doi:10.1016/j.cell.2015.05.002

Madisen L, Mao T, Koch H, Zhuo JM, Berenyi A, Fujisawa S, Hsu YW, Garcia AJ III, Gu X, Zanella S, et al. 2012. A toolbox of Cre-dependent optogenetic transgenic mice for light-induced activation and silencing. Nat Neurosci 15: 793-802. doi:10.1038/nn.3078

Maimon BE, Zorzos AN, Bendell R, Harding A, Fahmi M, Srinivasan S, Calvaresi P, Herr HM. 2017. Transdermal optogenetic peripheral nerve stimulation. J Neural Eng 14: 034002. doi:10.1088/1741-2552/aa5e20

Maksimovic S, Nakatani M, Baba Y, Nelson AM, Marshall KL, Wellnitz SA, Firozi P, Woo SH, Ranade S, Patapoutian A, et al. 2014. Epidermal Merkel cells are mechanosensory cells that tune mammalian touch receptors. Nature 509: 617-621. doi:10.1038/nature13250

Maljaars PW, Peters HP, Mela DJ, Masclee AA. 2008. Ileal brake: A sensible food target for appetite control. A review. Physiol Behav 95: 271-281. doi:10.1016/j.physbeh. 2008.07.018

Mattis J, Tye KM, Ferenczi EA, Ramakrishnan C, O’Shea DJ, Prakash R, Gunaydin LA, Hyun M, Fenno LE, Gradinaru V, et al. 2012. Principles for applying optogenetic tools derived from direct comparative analysis of microbial opsins. Nat Methods 9: 159-172. doi:10.1038/nmeth.1808

Mazzone SB, Undem BJ. 2016. Vagal afferent innervation of the airways in health and disease. Physiol Rev 96: 975-1024. doi:10.1152/physrev.00039.2015

McConalogue K, Furness JB. 1994. Gastrointestinal neurotransmitters. Baillieres Clin Endocrinol Metab 8: 51-76. doi:10.1016/S0950-351X(05)80226-5

McCorry LK. 2007. Physiology of the autonomic nervous system. Am J Pharm Educ 71: 78. doi:10.5688/aj710478

Meyers EE, Kronemberger A, Lira V, Rahmouni K, Stauss HM. 2016. Contrasting effects of afferent and efferent vagal nerve stimulation on insulin secretion and blood glucose regulation. Physiol Rep 4: e12718. doi:10.14814/ phy2.12718

Michoud F, Sottas L, Browne LE, Asboth L, Latremoliere A, Sakuma M, Courtine G, Woolf CJ, Lacour SP. 2018. Optical cuff for optogenetic control of the peripheral nervous system. J Neural Eng 15: 015002. doi:10.1088/1741-2552/ aa9126

Montgomery KL, Yeh AJ, Ho JS, Tsao V, Mohan Iyer S, Grosenick L, Ferenczi EA, Tanabe Y, Deisseroth K, Delp SL, et al. 2015. Wirelessly powered, fully internal optogenetics for brain, spinal and peripheral circuits in mice. Nat Methods 12: 969-974. doi:10.1038/nmeth.3536

Montgomery KL, Iyer SM, Christensen AJ, Deisseroth K, Delp SL. 2016. Beyond the brain: Optogenetic control in the spinal cord and peripheral nervous system. Sci Transl Med 8: 337rv5. doi:10.1126/scitranslmed.aad7577 
R.B. Chang

Murphy MB, Elliott WJ. 1990. Dopamine and dopamine receptor agonists in cardiovascular therapy. Crit Care Med 18: S14-S18. doi:10.1097/00003246-19900100200003

Nademanee K, Taylor R, Bailey WE, Rieders DE, Kosar EM. 2000. Treating electrical storm: Sympathetic blockade versus advanced cardiac life support-guided therapy. Circulation 102: 742-747. doi:10.1161/01.CIR.102.7.742

Nagel G, Brauner M, Liewald JF, Adeishvili N, Bamberg E Gottschalk A. 2005. Light activation of channelrhodopsin-2 in excitable cells of Caenorhabditis elegans triggers rapid behavioral responses. Curr Biol 15: 2279-2284. doi:10.1016/j.cub.2005.11.032

Nonomura K, Woo SH, Chang RB, Gillich A, Qiu Z, Francisco AG, Ranade SS, Liberles SD, Patapoutian A. 2017. Piezo2 senses airway stretch and mediates lung inflationinduced apnoea. Nature 541: 176-181. doi:10.1038/nature20793

O’Reardon JP, Cristancho P, Peshek AD. 2006. Vagus nerve stimulation (VNS) and treatment of depression: To the brainstem and beyond. Psychiatry (Edgmont) 3: 54-63.

Paintal AS. 1973. Vagal sensory receptors and their reflex effects. Physiol Rev 53: 159-227. doi:10.1152/physrev. 1973.53.1.159

Park SI, Brenner DS, Shin G, Morgan CD, Copits BA, Chung HU, Pullen MY, Noh KN, Davidson S, Oh SJ, et al. 2015. Soft, stretchable, fully implantable miniaturized optoelectronic systems for wireless optogenetics. Nat Biotechnol 33: $1280-1286$. doi:10.1038/nbt.3415

Park S, Bandi A, Lee CR, Margolis DJ. 2016. Peripheral optogenetic stimulation induces whisker movement and sensory perception in head-fixed mice. eLife 5: e14140.

Pavlov VA, Tracey KJ. 2017. Neural regulation of immunity: molecular mechanisms and clinical translation. Nat Neurosci 20: 156-166. doi:10.1038/nn.4477

Pavlov VA, Chavan SS, Tracey KJ. 2018. Molecular and functional neuroscience in immunity. Annu Rev Immunol 36: 783-812. doi:10.1146/annurev-immunol042617-053158

Rodda LB, Lu E, Bennett ML, Sokol CL, Wang X, Luther SA, Barres BA, Luster AD, Ye CJ, Cyster JG. 2018. Single-cell RNA sequencing of lymph node stromal cells reveals niche-associated heterogeneity. Immunity 48: 10141028.e6. doi:10.1016/j.immuni.2018.04.006

Rogers RC, McTigue DM, Hermann GE. 1995. Vagovagal reflex control of digestion: Afferent modulation by neural and "endoneurocrine" factors. Am J Physiol 268: G1-G10.

Rossi MA, Go V, Murphy T, Fu Q, Morizio J, Yin HH. 2015. A wirelessly controlled implantable LED system for deep brain optogenetic stimulation. Front Integr Neurosci 9: 8.

Rush AJ, George MS, Sackeim HA, Marangell LB, Husain MM, Giller C, Nahas Z, Haines S, Simpson RK Jr, Goodman R. 2000. Vagus nerve stimulation (VNS) for treatment-resistant depressions: A multicenter study. Biol Psychiatry 47: 276-286. doi:10.1016/S0006-3223 (99)00304-2

Sabbah HN, Ilsar I, Zaretsky A, Rastogi S, Wang M, Gupta RC. 2011. Vagus nerve stimulation in experimental heart failure. Heart Fail Rev 16: 171-178. doi:10.1007/s10741010-9209-z
Sajgo S, Ali S, Popescu O, Badea TC. 2016. Dynamic expression of transcription factor Brn $3 \mathrm{~b}$ during mouse cranial nerve development. J Comp Neurol 524: 1033-1061. doi:10.1002/cne.23890

Samineni VK, Mickle AD, Yoon J, Grajales-Reyes JG, Pullen MY, Crawford KE, Noh KN, Gereau GB, Vogt SK, Lai $\mathrm{HH}$, et al. 2017a. Optogenetic silencing of nociceptive primary afferents reduces evoked and ongoing bladder pain. Sci Rep 7: 15865. doi:10.1038/s41598-017-16129-3

Samineni VK, Yoon J, Crawford KE, Jeong YR, McKenzie KC, Shin G, Xie Z, Sundaram SS, Li Y, Yang MY, et al. 2017b. Fully implantable, battery-free wireless optoelectronic devices for spinal optogenetics. Pain 158: 2108 2116. doi:10.1097/j.pain.0000000000000968

Schachter SC, Saper CB. 1998. Vagus nerve stimulation. Epilepsia 39: 677-686. doi:10.1111/j.1528-1157.1998. tb01151.x

Siefring M. 2017. FDA Releases gammaCore ${ }^{\circledR}$, the first noninvasive vagus nerve stimulation therapy applied at the neck for acute treatment of pain associated with episodic cluster headache in adult patients. electroCore, https://www.electrocore.com/news/fda-releases-gammacorethe-first-non-invasive-vagus-nerve-stimulation-therapy-app lied-at-the-neck-for-acute-treatment-of-pain-associatedwith-episodic-cluster-headache-in-adult-patients.

Sisley S, Gutierrez-Aguilar R, Scott M, D'Alessio DA, Sandoval DA, Seeley RJ. 2014. Neuronal GLP1R mediates liraglutide's anorectic but not glucose-lowering effect. J Clin Invest 124: 2456-2463. doi:10.1172/JCI72434

Smear M, Resulaj A, Zhang J, Bozza T, Rinberg D. 2013. Multiple perceptible signals from a single olfactory glomerulus. Nat Neurosci 16: 1687-1691. doi:10.1038/nn.3519

Smith J, Shah A, Lee YK, Brien BO, Kullman D, Sridharan A, Muthuswamy J, Christen JB. 2016. Optogenetic neurostimulation of auricular vagus using flexible OLED display technology to treat chronic inflammatory disease and mental health disorders. Electron Lett 52: 900-902. doi:10.1049/el.2015.3450

Sparta DR, Stamatakis AM, Phillips JL, Hovelsø N, van Zessen R, Stuber GD. 2012. Construction of implantable optical fibers for long-term optogenetic manipulation of neural circuits. Nat Protoc 7: 12-23. doi:10.1038/ nprot.2011.413

Towne C, Montgomery KL, Iyer SM, Deisseroth K, Delp SL. 2013. Optogenetic control of targeted peripheral axons in freely moving animals. PLoS ONE 8: e72691. doi: 10.1371/journal.pone.0072691

Trankner D, Hahne N, Sugino K, Hoon MA, Zuker C. 2014. Population of sensory neurons essential for asthmatic hyperreactivity of inflamed airways. Proc Natl Acad Sci 111: 11515-11520. doi:10.1073/pnas.1411032111

Travagli RA, Anselmi L. 2016. Vagal neurocircuitry and its influence on gastric motility. Nat Rev Gastroenterol Hepatol 13: 389-401. doi:10.1038/nrgastro.2016.76

Urban DJ, Roth BL. 2015. DREADDs (designer receptors exclusively activated by designer drugs): Chemogenetic tools with therapeutic utility. Annu Rev Pharmacol Toxicol 55: 399-417. doi:10.1146/annurev-pharmtox010814-124803

Uthman BM. 2000. Vagus nerve stimulation for seizures. Arch Med Res 31: 300-303. doi:10.1016/S0188-4409(00) 00060-6 
Wang H, Zylka MJ. 2009. Mrgprd-expressing polymodal nociceptive neurons innervate most known classes of substantia gelatinosa neurons. J Neurosci 29: 13202-13209. doi:10.1523/jneurosci.3248-09.2009

Wang J, Kollarik M, Ru F, Sun H, McNeil B, Dong X, Stephens G, Korolevich S, Brohawn P, Kolbeck R, et al. 2017. Distinct and common expression of receptors for inflammatory mediators in vagal nodose versus jugular capsaicin-sensitive/TRPV1-positive neurons detected by low input RNA sequencing. PLoS ONE 12: e0185985.

Wehrwein EA, Orer HS, Barman SM. 2016. Overview of the anatomy, physiology, and pharmacology of the autonomic nervous system. Compr Physiol 6: 1239-1278. doi:10.1002/cphy.c150037

Wentz CT, Bernstein JG, Monahan P, Guerra A, Rodriguez A, Boyden ES. 2011. A wirelessly powered and controlled device for optical neural control of freely-behaving animals. J Neural Eng 8: 046021. doi:10.1088/1741-2560/8/4/ 046021

Widdicombe J. 2001. Airway receptors. Respir Physiol 125: 3-15. doi:10.1016/S0034-5687(00)00201-2

Williams EK, Chang RB, Strochlic DE, Umans BD, Lowell BB, Liberles SD. 2016. Sensory neurons that detect stretch and nutrients in the digestive system. Cell 166: 209-221. doi:10.1016/j.cell.2016.05.011

Wolter A. 2018 March 27. Nuvaira announces 1st patient treated in RELIEF-1 study evaluating new approach for asthma treatment. GlobeNewswire, https://www.nuvaira. com/nuvaira-announces-1st-patient-treated-in-relief-1study-evaluating-new-approach-for-asthma-treatment

Woodward ER. 1987. The history of vagotomy. Am J Surg 153: 9-17. doi:10.1016/0002-9610(87)90195-4

Yeh AJ, Ho JS, Tanabe Y, Neofytou E, Beygui RE, Poon AS. 2013. Wirelessly powering miniature implants for
Optogenetic Control of Peripheral Nervous System

optogenetic stimulation. Appl Phys Lett 103: 163701. doi:10.1063/1.4825272

Yizhar O, Fenno LE, Prigge M, Schneider F, Davidson TJ, O'Shea DJ, Sohal VS, Goshen I, Finkelstein J, Paz JT, et al. 2011. Neocortical excitation/inhibition balance in information processing and social dysfunction. Nature 477: 171-178. doi:10.1038/nature10360

Yuan H, Silberstein SD. 2016a. Vagus nerve and vagus nerve stimulation, a comprehensive review. Part I. Headache 56: 71-78. doi:10.1111/head.12647

Yuan H, Silberstein SD. 2016b. Vagus nerve and vagus nerve stimulation, a comprehensive review. Part II. Headache 56: 259-266. doi:10.1111/head.12650

Zeng H, Madisen L. 2012. Mouse transgenic approaches in optogenetics. Prog Brain Res 196: 193-213. doi:10.1016/ B978-0-444-59426-6.00010-0

Zhang F, Wang LP, Brauner M, Liewald JF, Kay K, Watzke N, Wood PG, Bamberg E, Nagel G, Gottschalk A, et al. 2007. Multimodal fast optical interrogation of neural circuitry. Nature 446: 633-639. doi:10.1038/nature05 744

Zhang F, Prigge M, Beyrière F, Tsunoda SP, Mattis J, Yizhar O, Hegemann P, Deisseroth K. 2008. Red-shifted optogenetic excitation: A tool for fast neural control derived from Volvox carteri. Nat Neurosci 11: 631-633. doi:10. $1038 / \mathrm{nn} .2120$

Zhang F, Vierock J, Yizhar O, Fenno LE, Tsunoda S, Kianianmomeni A, Prigge M, Berndt A, Cushman J, Polle J, et al. 2011. The microbial opsin family of optogenetic tools. Cell 147: 1446-1457. doi:10.1016/j.cell.2011.12.004

Zhuo H, Ichikawa H, Helke CJ. 1997. Neurochemistry of the nodose ganglion. Prog Neurobiol 52: 79-107. doi:10. 1016/S0301-0082(97)00003-8 


\section{$\&_{\mathrm{CSH}}^{\infty}$ \& Cold Spring Harbor

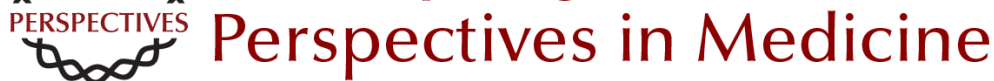

\section{Optogenetic Control of the Peripheral Nervous System}

Rui B. Chang

Cold Spring Harb Perspect Med 2019; doi: 10.1101/cshperspect.a034397 originally published online February 11, 2019

\section{Subject Collection Bioelectronic Medicine}

Neural Control of Inflammation: Bioelectronic Medicine in Treatment of Chronic Inflammatory

Disease

Michael Eberhardson, Laura Tarnawski, Monica Centa, et al.

Noninvasive Neuromodulation of Peripheral Nerve Pathways Using Ultrasound and Its Current Therapeutic Implications Christopher Puleo and Victoria Cotero

Enteric Neuromodulation for the Gut and Beyond Yogi A. Patel and Pankaj J. Pasricha

\section{Optogenetic Control of the Peripheral Nervous} System

Rui B. Chang

Closed-Loop Neuromodulation in Physiological and Translational Research Stavros Zanos

Electrical Impedance Methods in Neuromuscular Assessment: An Overview Seward B. Rutkove and Benjamin Sanchez

Optogenetic Medicine: Synthetic Therapeutic

Solutions Precision-Guided by Light Haifeng Ye and Martin Fussenegger

Technobiology's Enabler: The Magnetoelectric Nanoparticle Sakhrat Khizroev
Bioelectronic Medicine: From Preclinical Studies on the Inflammatory Reflex to New Approaches in Disease Diagnosis and Treatment

Valentin A. Pavlov, Sangeeta S. Chavan and Kevin J. Tracey

Vagus Nerve Stimulation and the Cardiovascular System Michael J. Capilupi, Samantha M. Kerath and Lance B. Becker

Harnessing the Inflammatory Reflex for the Treatment of Inflammation-Mediated Diseases Yaakov A. Levine, Michael Faltys and David Chernoff

Recording and Decoding of Vagal Neural Signals Related to Changes in Physiological Parameters and Biomarkers of Disease

Theodoros P. Zanos

Restoring Movement in Paralysis with a

Bioelectronic Neural Bypass Approach: Current

State and Future Directions Chad E. Bouton

Bioelectronic Medicine--Ethical Concerns Samuel Packer, Nicholas Mercado and Anita Haridat

Use of Bioelectronics in the Gastrointestinal Tract Larry Miller, Aydin Farajidavar and Anil Vegesna

Vagus Nerve Stimulation at the Interface of BrainGut Interactions

Bruno Bonaz, Valérie Sinniger and Sonia Pellissier

For additional articles in this collection, see http://perspectivesinmedicine.cshlp.org/cgi/collection/ 